\title{
A partial skeleton of Septencoracias from the early Eocene London Clay reveals derived features of bee-eaters (Meropidae) in a putative stem group roller (Aves, Coracii)
}

\author{
Gerald Mayr ${ }^{1}$
}

Received: 2 February 2021 / Revised: 8 March 2021 / Accepted: 1 July 2021 / Published online: 13 September 2021

(C) The Author(s) 2021

\begin{abstract}
A partial skeleton of the putative stem group roller Septencoracias is described from the early Eocene London Clay of Waltonon-the-Naze (Essex, UK). With an age of about 55 million years, the bones represent one of the earliest fossil records of a coraciiform bird. The new fossil reveals that the proximal pedal phalanges of the three anterior toes of Septencoracias exhibit markedly widened distal ends. This distinctive trait is not found in other representatives of the Coracii, but occurs in the Meropidae (bee-eaters). The quadrate likewise exhibit a derived characteristic of the Meropidae, and the beak is narrower than in rollers. These previously unnoticed features are of particular interest, because the Meropidae result as the sister taxon of the Coracii in sequence-based analyses. Calibrated molecular data suggest that the divergence between the Coracii and the Meropidae occurred at 55.6 Ma, with the new fossil being only slightly younger than this date. However, phylogenetic analyses recovered Septencoracias within the Coracii, so that the derived features shared with the Meropidae most likely are either plesiomorphic and were lost in the Coracii, or they represent parallelisms that evolved convergently in Septencoracias and the Meropidae. In any case, these traits suggest that Septencoracias differed from extant rollers in its ecological preferences and foraging mode.
\end{abstract}

Keywords Coracii $\cdot$ Fossil birds $\cdot$ Walton-on-the-Naze $\cdot$ Ypresian

\section{Introduction}

The coraciiform taxon Coracii includes colourful birds known as rollers. The extant species only occur in the Old World, with true rollers (Coraciidae) being widely distributed across Eurasia, Africa, and Australia, whereas ground rollers (Brachypteraciidae) are confined to Madagascar.

The Coracii were long considered to be closely related to bee-eaters (Meropidae), kingfishers (Alcedinidae), motmots (Momotidae), and todies (Todidae). However, the latter four taxa were traditionally often assigned to a clade Alcediniformes (e.g. Feduccia 1977; Mayr 1998), whereas current molecular analyses suggest a sister group relationship between

Gerald Mayr

Gerald.Mayr@senckenberg.de

1 Senckenberg Research Institute and Natural History Museum Frankfurt, Ornithological Section, Senckenberganlage 25, 60325 Frankfurt am Main, Germany the Meropidae and the Coracii, with the Alcedinides (Alcedinidae, Momotidae, Todidae) being the sister taxon of the clade including Meropidae and Coracii (Prum et al. 2015; McCullough et al. 2019; Kuhl et al. 2021). An earlier analysis by Hackett et al. (2008) likewise did not support monophyly of the Alcediniformes, but resulted in a sister group relationship between the Meropidae and a clade including the Coracii and the Alcedinides.

The Palaeogene fossil record of rollers is fairly substantial and includes various taxa that are successive sister taxa of the extant species. Most similar to extant Coracii are two species of the taxon Geranopterus, G. alatus, and G. milneedwardsi (Geranopteridae), which occur in late Eocene deposits of the Quercy fissure fillings in France (Mayr and Mourer-Chauviré 2000). Phylogenetic analyses recover Geranopterus as the closest Palaeogene relative of crown group Coracii (Mayr et al. 2004; Clarke et al. 2009). The sister taxon of the clade formed by Geranopterus and crown group Coracii is Paracoracias occidentalis from the North American Green River Formation (Clarke et al. 
2009); the exact provenance of the holotype is unknown, but Grande (2013: 243) hypothesised that it stems from the middle Eocene Laney Shale Member. P. occidentalis may therefore be roughly coeval to Eocoracias brachyptera (Eocoraciidae) from the early Eocene (48 million years ago [Ma]) of Messel in Germany, which is known from several complete skeletons (Mayr and Mourer-Chauviré 2000). Current analyses suggest that Eocoracias is the sister taxon of a clade including Paracoracias, Geranopterus, and crown group Coracii (Clarke et al. 2009; Bourdon et al. 2016). A partial skull and associated postcranial bones of an unnamed stem group roller from the London Clay of the Isle of Sheppey (51.5-53.5 Ma) were furthermore described by Mayr and Walsh (2018).

The earliest diverging stem group rollers belong to the taxon Primobucconidae, which was established for Primobucco mcgrewi from early Eocene (51-52 Ma) layers of the Fossil Butte Member of the Green River Formation (Mayr et al. 2004; Ksepka and Clarke 2010). Two species of Primobucco, P. perneri and P. frugilegus, also occur in Messel, and a tarsometatarsus of an unnamed putative primobucconid was described from the early Eocene ( 51-52 Ma) of France (Mayr et al. 2004). Primobucconids were smaller than the species of Eocoracias, Paracoracias, Geranopterus, and extant Coracii, from which they also differ in some plesiomorphic skeletal characteristics.

Another small, roller-like bird, Septencoracias morsensis from the early Eocene ( $\sim 54 \mathrm{Ma})$ Fur Formation in Denmark, was also tentatively assigned to the Primobucconidae (Bourdon et al. 2016). The species is based on a wellpreserved articulated skeleton, which allows, however, the recognition of only a limited amount of skeletal details. A tarsometatarsus from the early Eocene (50.5-52 Ma) of Egem in Belgium was tentatively referred to Septencoracias by Mayr and Smith (2019).

Because rollers today only occur in the Old World, the occurrence of stem group representatives of the Coracii in the Eocene of North America is already remarkably from a biogeographic point of view (Mayr 2009). Even more unexpected would be their recently proposed occurrence in South America, which was based on a putative stem group roller from the early Eocene (52 Ma) of Argentina (Degrange et al. 2021). However and as detailed in the discussion, this species (Ueekenkcoracias tambussiae) is markedly different from stem group rollers, and its assignment to the Coracii is likely to be erroneous.

Here, isolated bones of Septencoracias are described from the early Eocene (54.6-55 Ma) London Clay of Walton-on-theNaze, Essex, UK. The fossils stem from the collection of the late Paul Bergdahl and were acquired by Senckenberg Research Institute Frankfurt. The bones belong to a single individual and show previously unknown osteological details, which potentially bear on the phylogenetic affinities of this species.

\section{Material and methods}

Institutional abbreviations: SMF, Senckenberg Research Institute Frankfurt; NMS, National Museums of Scotland, Edinburgh, UK; SMNK, Staatliches Museum für Naturkunde Karlsruhe, Germany.

To assess the affinities of the fossil, a phylogenetic analysis of 58 morphological characters was performed (see appendices for character descriptions and matrix). For this analysis, Septencoracias morsensis was scored after the holotype, the new specimen reported in the present study, and a tarsometatarsus described by Mayr and Smith (2019).

In a second analysis, 15 "dummy" characters were added to constrain the topology of the extant taxa according to the results of current molecular analyses, which support a clade including the Meropidae and Coracii (Prum et al. 2015; Kuhl et al. 2021). The characters added to this constrained analysis were scored as "1" for the Meropidae, Coraciidae, and Brachypteraciidae; as "0" for all other extant taxa; and as unknown ("?") for the fossil taxa.

The analyses were run with the heuristic search modus of NONA 2.0 (Goloboff 1993) through the WINCLADA 1.00.08 interface (Nixon 2002), using the commands hold 10000 , mult*1000, hold/10, and max*. Bootstrap support values were calculated with 1000 replicates, ten searches holding ten trees per replicate, and TBR branch swapping without max*. Outgroup comparisons were made with the Falconidae. Tree length (L), consistency index $(\mathrm{CI})$, and retention index (RI) were calculated.

\section{Systematic palaeontology}

Aves Linnaeus, 1758

Coraciiformes Forbes, 1884

?Coracii Wetmore and Miller, 1926

Septencoracias Bourdon et al., 2016

Emended diagnosis: In addition to the characters listed by Bourdon et al. (2016), the taxon Septencoracias is diagnosed by widened distal sections of the proximal phalanges of the three anterior toes.

Septencoracias cf. morsensis Bourdon et al., 2016

Referred specimen: SMF Av 655: partial skeleton including large portions of the mandible, the left jugal arch, left quadrate, nine vertebrae or fragments thereof, right carpometacarpus distal section of right radius, nearly complete right tibiotarsus, distal section of left tibiotarsus, right fibula, fragment of left trochlea metatarsi IV, and most pedal phalanges of the left foot (Fig. 1); the fossil was found in 1988 by Paul Bergdahl (original collector's number BC 8813).

Locality and horizon: Walton-on-the-Naze, Essex, UK; Walton Member of the London Clay Formation (previously 

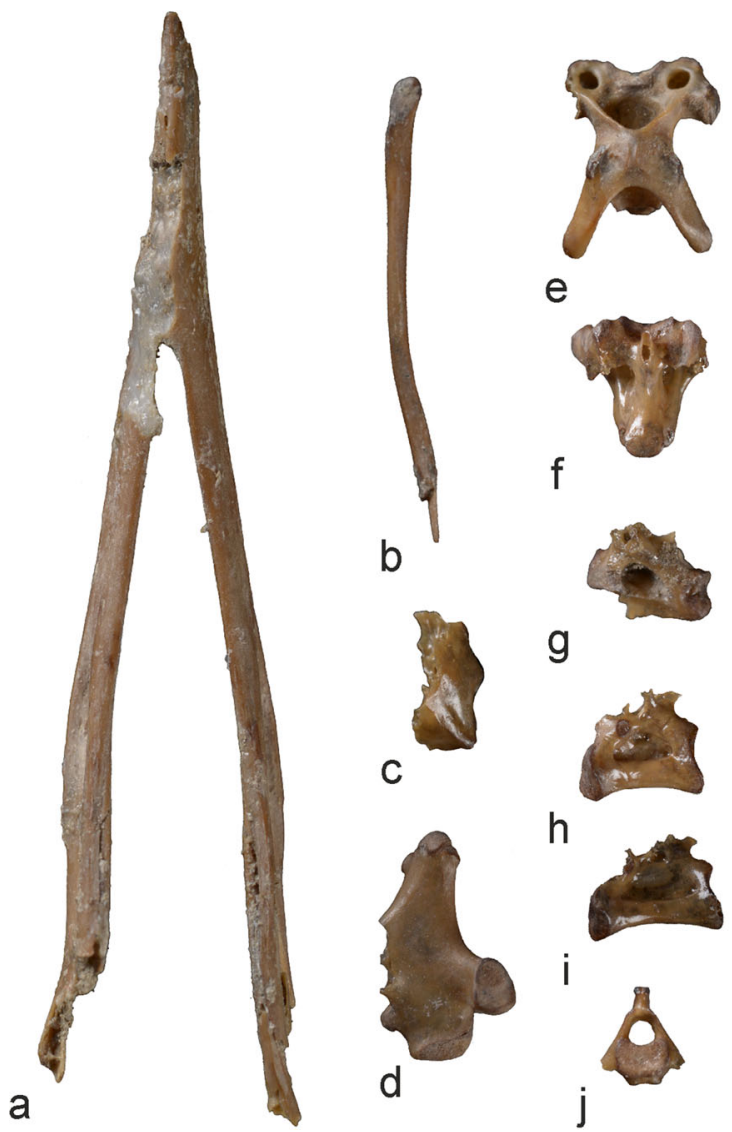

e
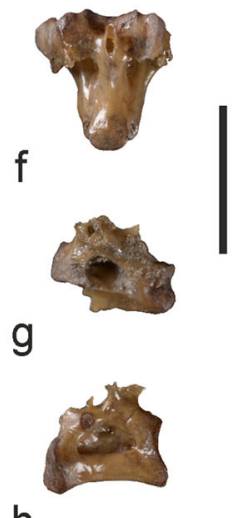

$\mathrm{h}$

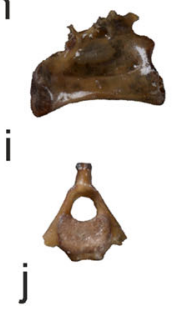

$\mathrm{m}$

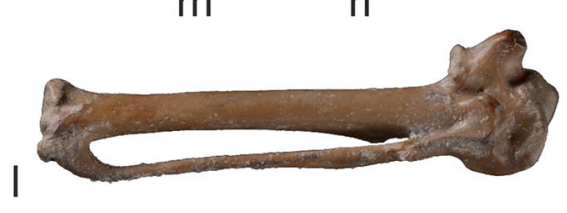

Caudal vertebra. $\mathbf{g}$ Distal section of right radius. I Right carpometacarpus. m Right tibiotarsus. $\mathbf{n}$ Distal portion of left tibiotarsus. o Right fibula. $\mathbf{p}$ Fragment of left trochlea metatarsi IV and pedal phalanges of left foot. Scale bar equals $5 \mathrm{~mm}$
Division A2; Jolley 1996; Aldiss 2012), early Eocene (early Ypresian; 54.6-55 Ma; Collinson et al. 2016).

Measurements (length in $\mathbf{m m}$; in brackets the dimension of the Septencoracias morsensis holotype; after Bourdon et al. 2016): Mandible, length as preserved, 36.9 [48.5]. Carpometacarpus, 18.1 [17.2/18.0]. Tibiotarsus, 29.0 [30.9]. Pedal phalanges, I1: 7.0 [8.3]; II1, 5.0 [5.4]; II2, 5.1 [5.1]; III1, 5.1 [5.4]; III2, 5.0 [5.2]; III3, 5.6 [5.7]; IV1, 3.3 [4.3]; IV2/IV3, 3.2 [3.7/3.5]; IV4, 4.3 [4.2], ungual phalanx, $>4.2$

Description and comparisons: The quadrate (Fig. 2a-f) lacks the processus orbitalis, but is otherwise complete. The bone corresponds to the quadrate of extant Coracii (Fig. 2i-1) in overall proportions, but shows some notable differences. As in the Meropidae (Fig. 2m, n), but unlike in the Coracii and Alcedinides (Alcedinidae, Momotidae, Todidae), the cotyla quadratojugalis is shallow; ventral of it, the tip of the condylus lateralis forms a distinct platform (a shallow cotyla quadratojugalis also occurs in the Trogonidae and the piciform Indicatoridae). The condylus medialis projects ventrally well beyond the condylus pterygoideus; it is, however, rostrocaudally more extensive and ventrally less prominent than in crown group Coracii, Meropidae, and the Alcedinides. The foramen pneumaticum mediale is situated in a ventral position at the base of the processus orbitalis, whereas it is more dorsally located in the Meropidae; the taxa of the Alcedinides lack a foramen pneumaticum mediale (Elzanowski and Boles 2015). Furthermore unlike in the Meropidae, Alcedinides, and Brachypteraciidae but as in the Coraciidae (and most other birds), there are no pneumatic foramina on the caudal surface of the processus oticus. The condylus caudalis (condylus laterocaudalis sensu Elzanowski and Boles 2015) is laterally extensive; this morphology was identified as a coraciiform apomorphy by Elzanowski and Boles (2015). On the processus oticus, capitulum squamosum and capitulum oticum are widely separated by a shallow incisura intercapitularis. On the lateral side of the processus oticus, immediately ventral of the capitulum squamosum, there is a small tubercle (tuberculum subcapitulare of Elzanowski and Boles 2015). As in crown group Coracii and 

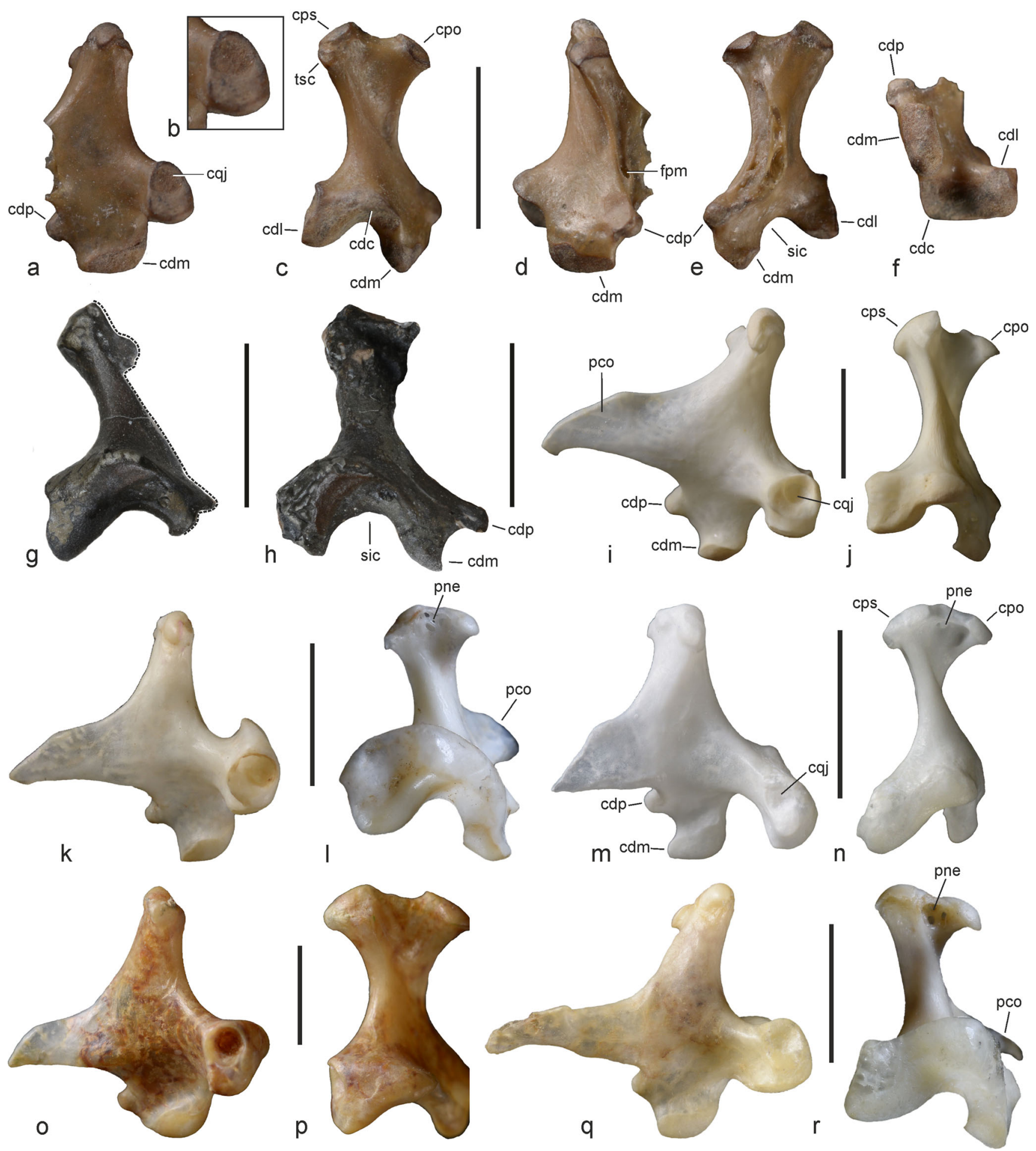

Fig. 2 Septencoracias cf. morsensis from the early Eocene London Clay of Walton-on-the-Naze (SMF Av 655); partial left quadrate in comparison to other fossil and extant taxa. a-f $S$. cf. morsensis, left quadrate in (a) lateral view with (b) detail of the cotyla quadratojugalis, (c) caudal view, (d) medial view, (e) cranial view, and (f) ventral view. $\mathbf{g}$ Left quadrate of NMS G.2014.54.1, the unnamed stem group roller from the Isle of Sheppey described by Mayr and Walsh (2018); surrounding matrix was digitally removed, the dashed line delimits the exposed portion of the bone (the missing part is hidden in matrix or overlain by other bones). $\mathbf{h}$ Right quadrate (mirrored) of NMS G.2014.54.1; surrounding matrix was digitally removed. i, j Coracias garrulus (Coraciidae), left quadrate in lateral (i) and caudal (j)

view. $\mathbf{k}$, I Atelornis pittoides (Brachypteraciidae), right quadrate (mirrored) in lateral (k) and caudal (I) view. m, n Merops nubicus (Meropidae), left quadrate in lateral $(\mathbf{m})$ and caudal $(\mathbf{n})$ view. o, p Leptosomus discolor (Leptosomidae), left quadrate in lateral (o) and caudal (p) view. q, r Momotus momota (Momotidae), right quadrate (mirrored) in lateral $(\mathbf{q})$ and caudal (r) view. $c d c$ condylus caudalis, $c d l$ condylus lateralis, $c d m$ condylus medialis, $c d p$ condylus pterygoideus, $c p o$ capitulum oticum, $c p s$ capitulum squamosum, $c q j$ cotyla quadratojugalis, $f p m$ foramen pneumaticum mediale, pco processus orbitalis, pne pneumatic openings, sic sulcus intercondylaris, tsc tuberculum subcapitulare. Scale bars equal $5 \mathrm{~mm}$ 


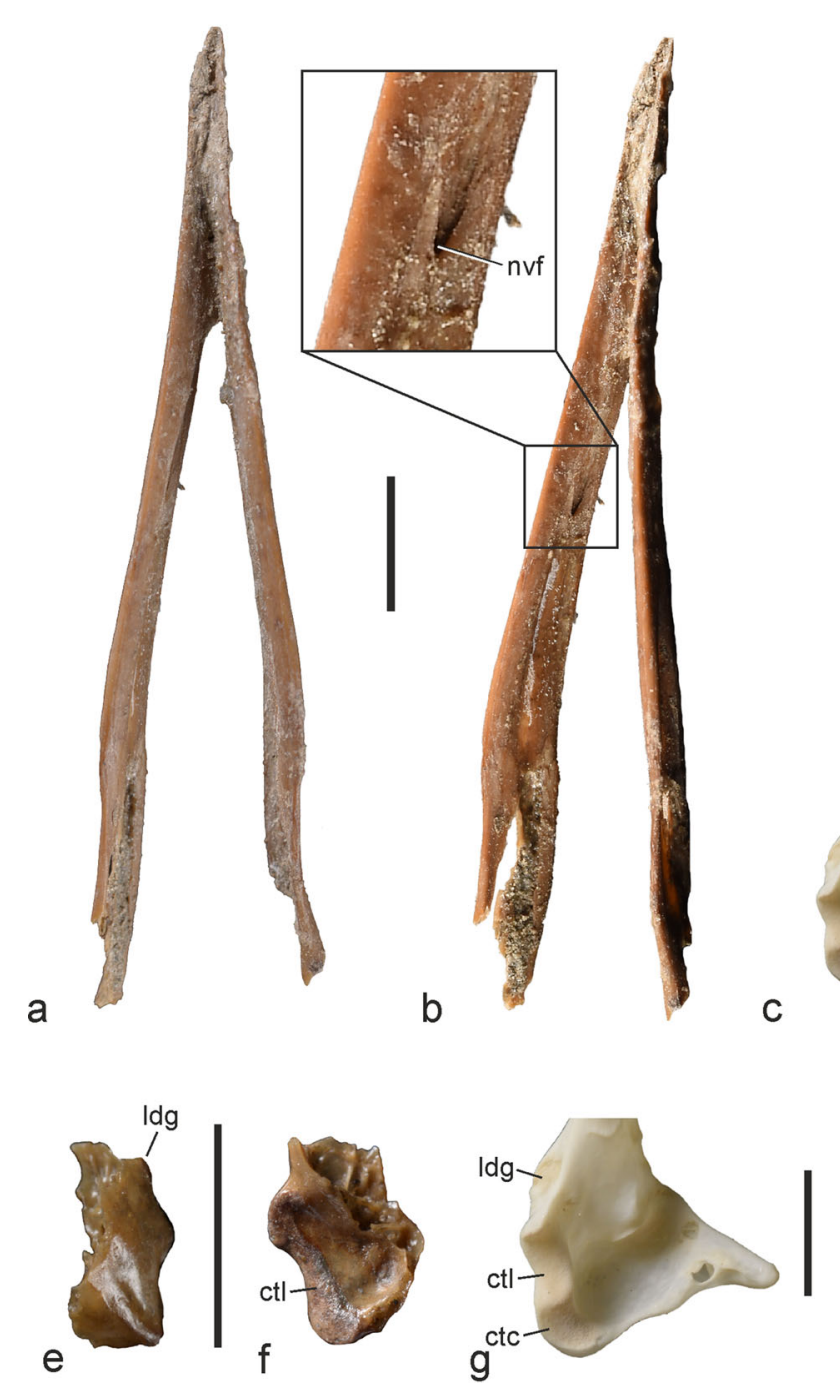

Fig. 3 Septencoracias cf. morsensis from the early Eocene London Clay of Walton-on-the-Naze (SMF Av 655), mandible, jugal arch, and vertebrae. a, b $S$. cf. morsensis, main portion of mandible in dorsal (a) and laterodorsal (b) view; the detail shows the neurovascular foramen on the medial surface of the mandibular ramus. c Mandible of Coracias garrulus (Coraciidae) in dorsal view. d Mandible of Merops nubicus (Meropidae) in dorsal view. e, $\mathbf{f} S$. cf. morsensis, fragment of caudal portion of left mandibular ramus in ventral (e) and dorsal (f) view. $\mathbf{g}$ C. garrulus, caudal

Momotidae, but unlike in the Trogonidae, Alcedinidae, and Upupidae, the condylus pterygoideus is not sharply delimited by a circumferential sulcus around its base. In addition to its somewhat smaller size, the quadrate of Septencoracias cf. morsensis from Walton-on-the-Naze is distinguished from the quadrate of an unnamed stem group representative of the Coracii from the London Clay of the Isle of Sheppey (Mayr and Walsh 2018) in that the condylus lateralis is less protruding and the processus mandibularis and the sulcus intercondylaris are mediolaterally narrower (Fig. 2g, h). The fossil also comprises
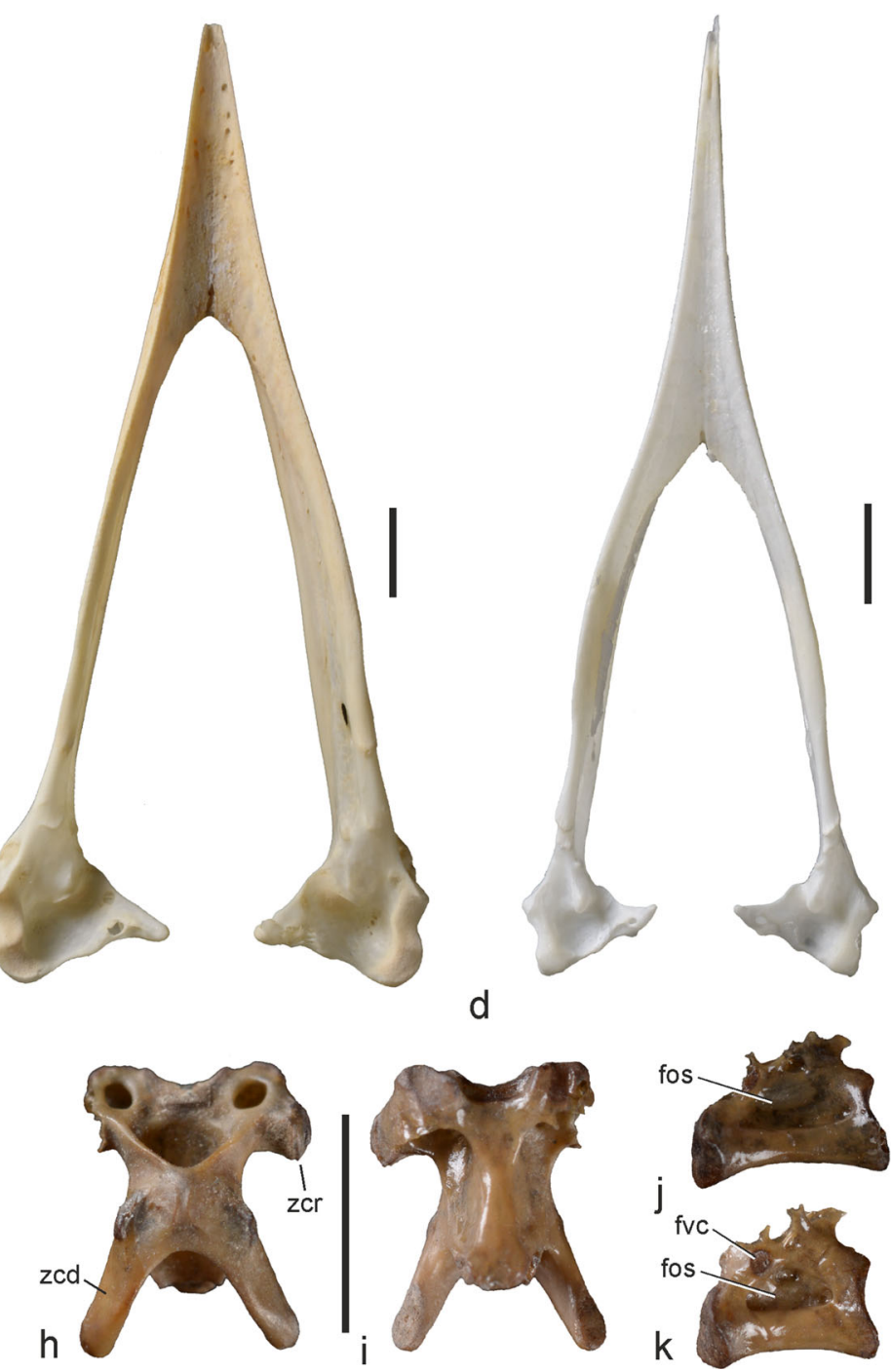

portion of left mandibular ramus in dorsal view. h, i $S$. cf. morsensis, cervical vertebra in dorsal (h) and ventral (i) view. j, k $S$. cf. morsensis, two thoracic vertebrae in left lateral view. ctc cotyla lateralis, $c t l$ cotyla lateralis, $f o s$ fossa on lateral surface of vertebral corpus, $f v c$ fovea costalis, $l d g$ laterally protruding ledge for insertion of musculus adductor mandibulae ossis quadrati, $n v f$ neurovascular foramen, $z c d$ zygapophysis caudalis, zcr zygapophysis cranialis. Scale bars equal $5 \mathrm{~mm}$; same scale for $\mathbf{h}-\mathbf{k}$

the left jugal arch (Fig. 1b); unlike in the Meropidae, its caudal end is not sharply kinked dorsally.

The long mandible (Figs. 1a, 3a, b) is much narrower mediolaterally than the mandibles of crown group Coracii (Fig. 3c), Eocoracias, Paracoracias, and the Primobucconidae. The pars symphysialis is moderately long and forms a concave trough. Unlike in extant Coracii and Meropidae, the medial surface of the mandibular ramus exhibits a large neurovascular foramen in its midsection (Fig. 3b). The holotype includes a fragment of the 


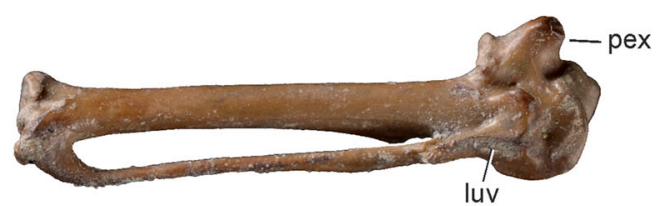

a
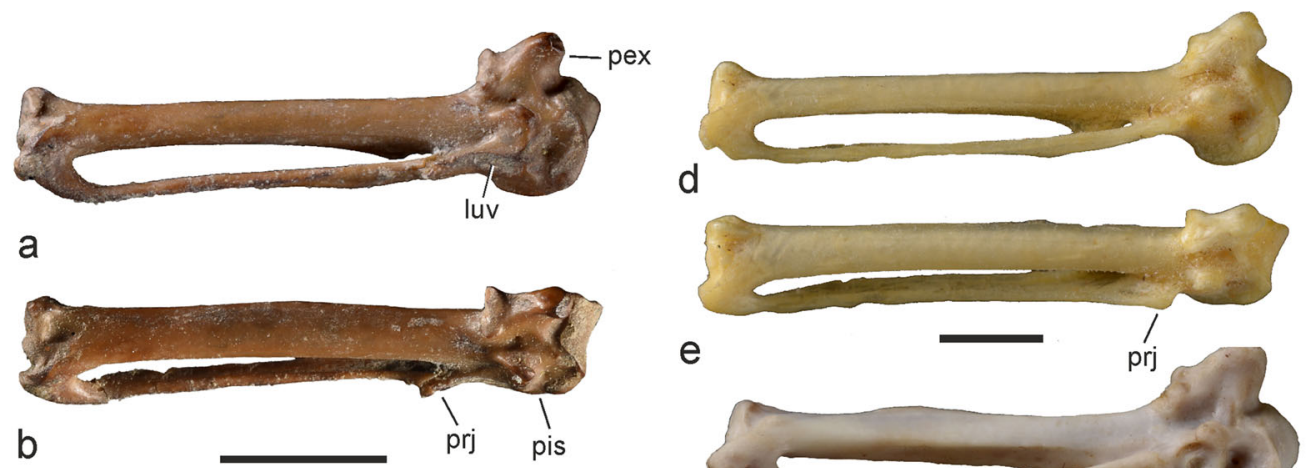

d

luv

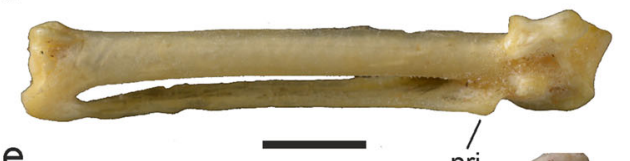

e

ntc
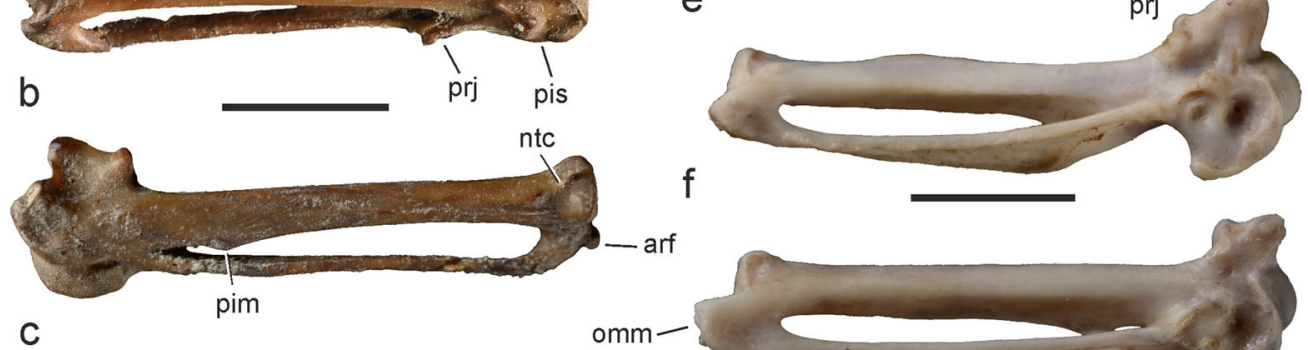

omm -
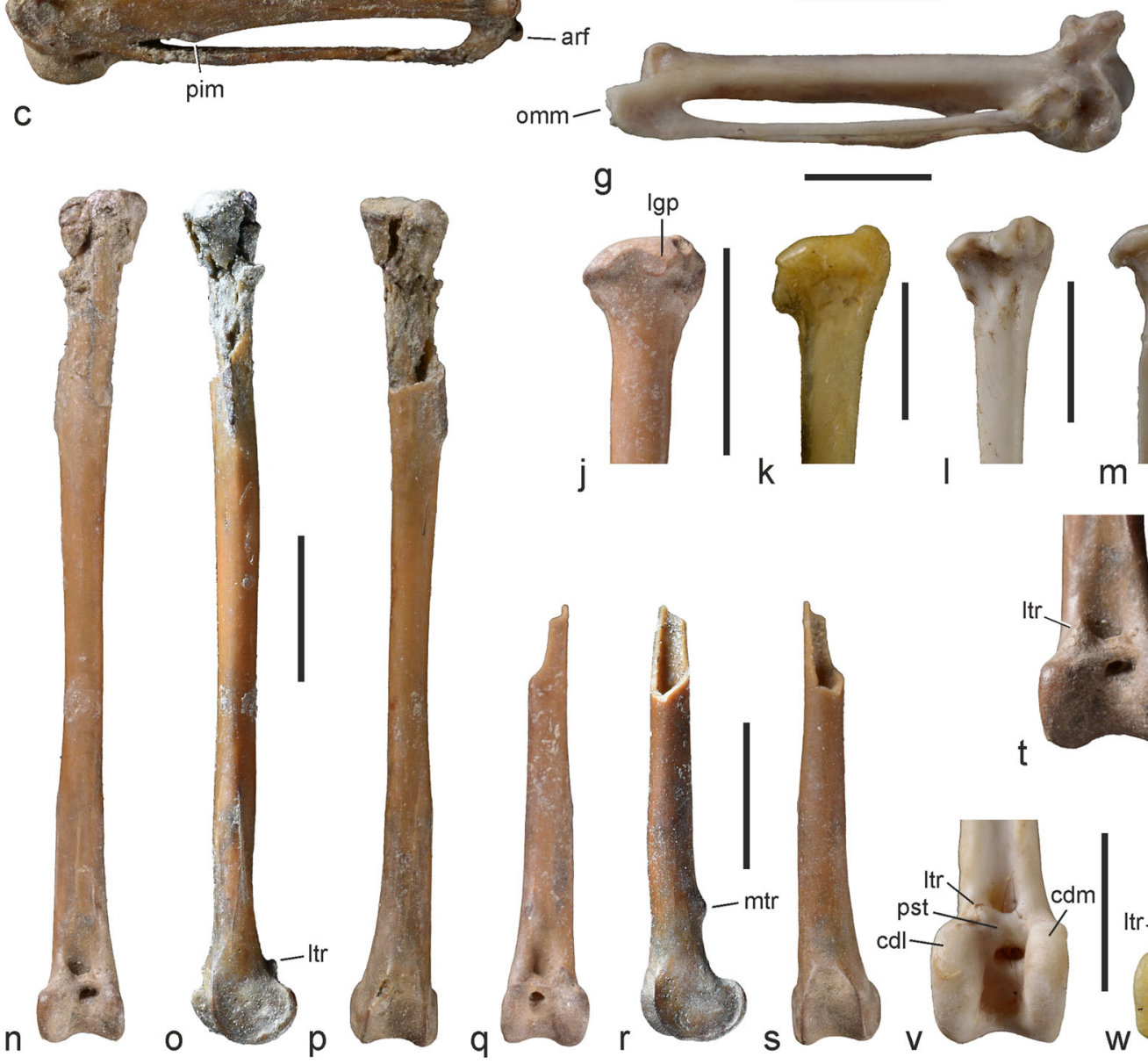

$9 \lg p$

$\mathrm{h}$

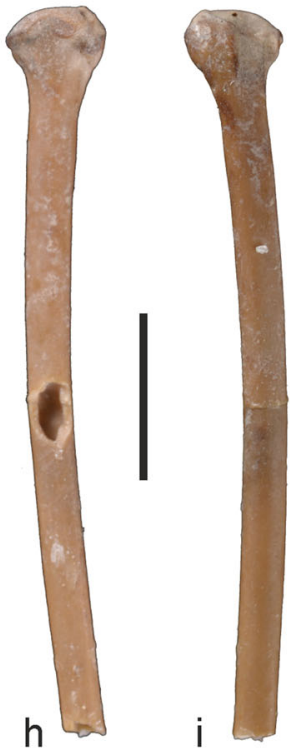

Fig. 4 Septencoracias cf. morsensis from the early Eocene London Clay of Walton-on-the-Naze (SMF Av 655), limb bones in comparison to extant Coraciidae, Brachypteraciidae, and Meropidae. a-c $S$. cf. morsensis, carpometacarpus in ventral (a), cranioventral (b), and dorsal (c) view. d, e Eurystomus glaucurus (Coraciidae), right carpometacarpus in ventral (d) and cranioventral (e) view. f Atelornis pittoides (Brachypteraciidae), right carpometacarpus in ventral view. g Merops apiaster (Meropidae), right carpometacarpus in ventral view. h, i $S$. cf. morsensis, distal section of right radius in ventral (h) and dorsal (i) view. $\mathbf{j}-\mathbf{m}$ distal end of right radius (ventral view) of $\mathbf{j} S$. cf. morsensis, $\mathbf{k}$ E. glaucurus, $\mathbf{1}$ A. pittoides, and $\mathbf{m}$ M. apiaster. $\mathbf{n}-\mathbf{p} S$. cf. morsensis, right tibiotarsus in cranial (n), lateral (o), and caudal (p) view. q-s $S$. cf.
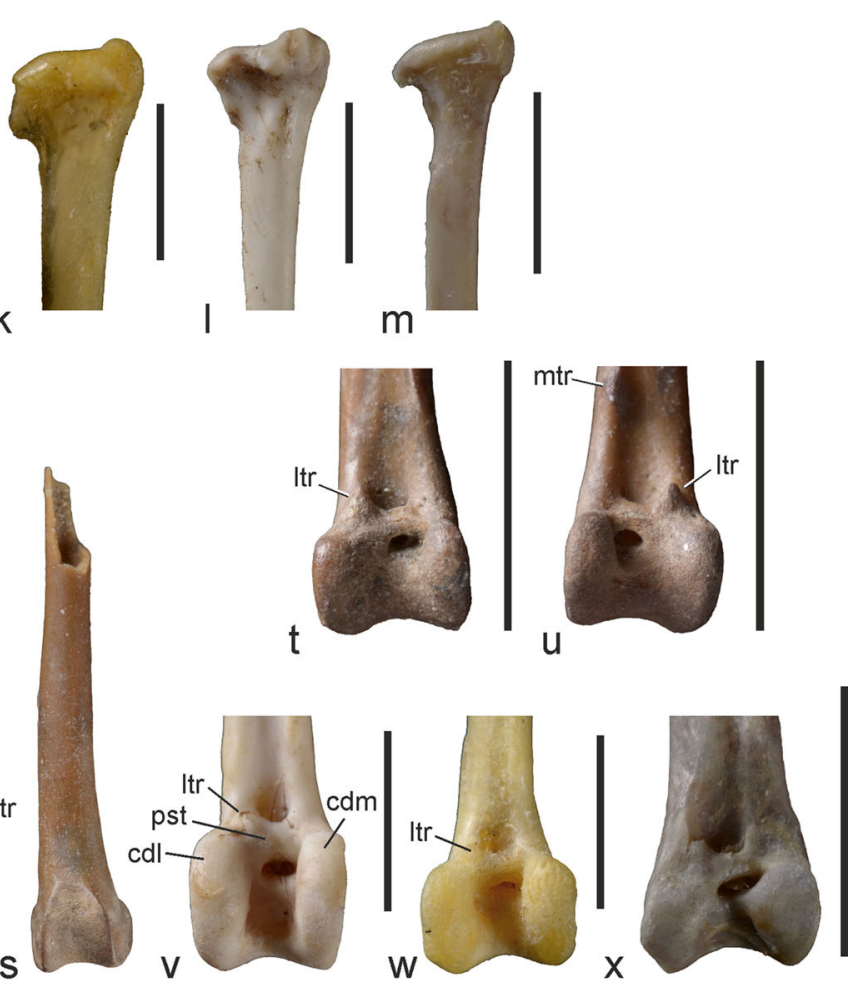

morsensis, distal portion of left tibiotarsus in cranial (q), medial (r), and caudal (s) view. t, u $S$. cf. morsensis, distal ends of right (t) and left (u) tibiotarsus in cranial view. $\mathbf{v}-\mathbf{x}$ distal end of right tibiotarsi (cranial view) of $\mathbf{v}$ A. pittoides, $\mathbf{w}$ E. glaucurus, and $\mathbf{x} M$. apiaster. arf articulation facet for phalanx proximalis digiti majoris, $c d l$ condylus lateralis, $c d m$ condylus medialis, $\lg p$ ligamental prominence, ltr lateral tuberositas retinaculi extenori, luv scar for insertion of ligamentum ulnometacarpale ventrale, $m t r$ medial tuberositas retinaculi extensori, $n t c$ notch in cranial margin of sulcus extensorius, omm distal projection formed by os metacarpale minus, pex processus extensorius, pim processus intermetacarpalis, pis processus pisiformis, $p r j$ ventral projection of os metacarpale minus, pst pons supratendineus. Scale bars equal $5 \mathrm{~mm}$ 
caudal end of the left mandibular ramus (Fig. 3e, f), which is distinguished from the corresponding portion of the caudal mandible of the Coracii in that there is no clear distinction between the cotyla lateralis and the cotyla caudalis (Fig. 3g). As in extant Coracii, there is a laterally protruding ledge for the insertion of the tendon of musculus adductor mandibulae ossis quadrati.

The specimen includes one nearly complete cervical vertebra as well as fragments of four cervicothoracic vertebrae, three thoracic vertebrae, and one caudal vertebra (Fig. 1e-j). The cervical vertebra (Fig. 3h, i) lacks a bony bridge from the corpus vertebrae to the processus costalis, which is present on at least the 4th to 6th cervical vertebrae of crown group Coracii. Unlike in extant Coracii and other coraciiform birds, the thoracic vertebrae are pleurocoelous, with elongate lateral depressions on the vertebral corpus (Fig. 3j, k).

The right carpometacarpus is complete (Fig. $4 \mathrm{a}-\mathrm{c}$ ). The processus extensorius is of similar shape to that of the Coraciidae (Fig. 4d, e) but less prominent than in the Brachypteraciidae (Fig. 4f); the trochlea carpalis is proportionally larger than in the Coraciidae. Caudal of the processus pisiformis, there is an elongate scar for insertion of ligamentum ulnometacarpale ventrale, which is less developed in extant rollers. The processus intermetacapalis is poorly developed. The proximal end of the os metacarpale minus exhibits a ventral projection, which is damaged in the fossil, but appears to have been less strongly developed than in crown group Coracii. The spatium intermetacarpale is slightly widening distally. The articulation facet for the phalanx proximalis digiti majoris (Fig. 4c) is well-defined and set off from the distal end of the os metacarpale majus by a distinct notch. Unlike in the Meropidae (Fig. 4g) and Alcedinides, however, the main portion of the os metacarpale minus does not project farther distally than the os metacarpale majus. Unlike in extant coraciiform birds, the cranial margin of the distal end of the sulcus extensorius forms a notch (Fig. 4c). On the dorsal surface of the symphysis metacarpalis distalis, there is a sulcus for musculus interosseus dorsalis.

The only other wing bone preserved in the specimen is the distal end of the right radius (Fig. 4h, i). No comparative data on the distal radius are available, but the centrally positioned and tubercle-like ligamental prominence on its ventral surface is better developed than in crown group Coracii.

The right tibiotarsus is nearly complete, but the proximal portion of the bone is damaged (Fig. $4 n-p$ ); of the left tibiotarsus, only the distal section is present (Fig. 4qs). On the distal end of the bone, the lateral tuberositas retinaculi extensori forms a prominent, edge-like projection immediately proximal of the condylus lateralis (Fig. $4 \mathrm{t}, \mathrm{u}$ ). A marked tuberositas retinaculi extensori also occurs in crown group Coracii (Fig. 4v, w) and the Alcedinidae, but is less developed in the Meropidae (Fig. 4x). The medial tuberositas retinaculi extensori is likewise prominent, but forms a proximodistally extensive ridge that is situated much farther proximally. The condyles are not as proximodistally elongated as in crown group Coracii, and unlike in the latter, the pons supratendineus is situated proximal of the condyles. The fossil also includes the proximal portion of the right fibula, which does not exhibit features of taxonomic or phylogenetic significance.

Of the tarsometatarsus, only a fragment of the left trochlea metatarsi IV is included in the specimen (Fig. 5b). As in other coraciiform birds, this trochlea has a subcylindrical shape and lacks a plantarly directed flange.

Altogether, eleven pedal phalanges of the left foot are preserved, including two unguals (Fig. 5a, b). As in the holotype of Septencoracias morsensis (Fig. 5c), the first phalanx of the hallux is very long and exceeds the other phalanges in length; the distal end of this phalanx bears a marked ventral sulcus, and the condyle forms two narrow and widely spaced rims. Unlike in the Meropidae (Fig. $5 \mathrm{~g}$ ) and the taxa of the Alcedinides, the proximal end of the first phalanx of the hallux is only slightly mediolaterally widened. The proximal pedal phalanges of the three anterior toes exhibit a distinctive morphology with unusally widened distal ends of proximal (first) phalanges of the three anterior toes. This widening is also present in the second phalanx of the third toe. The proximal end of the first phalanx of the second toe exhibits a sulcus along its plantar surface. The tuberculum extensorium of the second phalanx of the third toe is strongly developed and proximally projected.

\section{Results of the phylogenetic analysis}

The primary analysis of the character matrix in the appendix results in five most parsimonious trees $(\mathrm{L}=119 ; \mathrm{CI}=0.52$; $\mathrm{RI}$ $=0.62$ ), the consensus tree of which is shown in Fig. 6. This analysis supported a clade including Septencoracias and other stem group Coracii, even though this clade was not retained in the bootstrap analysis, and the interrelationships of the taxa within this clade were unresolved.

Six characters were optimised as apomorphies of stem and crown group rollers in the analysis: skull with strongly elongated processus postorbitales (ch. 3); skull with very large foramen for the ramus occipitalis of the arteria ophthalmica externa (ch. 6); os metacarpale minus of carpometacarpus not protruding much farther distally than os metacarpale majus (ch. 36); tibiotarsus, distal end with the lateral tuberositas retinaculi extensori forming a prominent, edge-like projection immediately proximal of the condylus lateralis (ch. 42); tarsometatarsus, foramen 

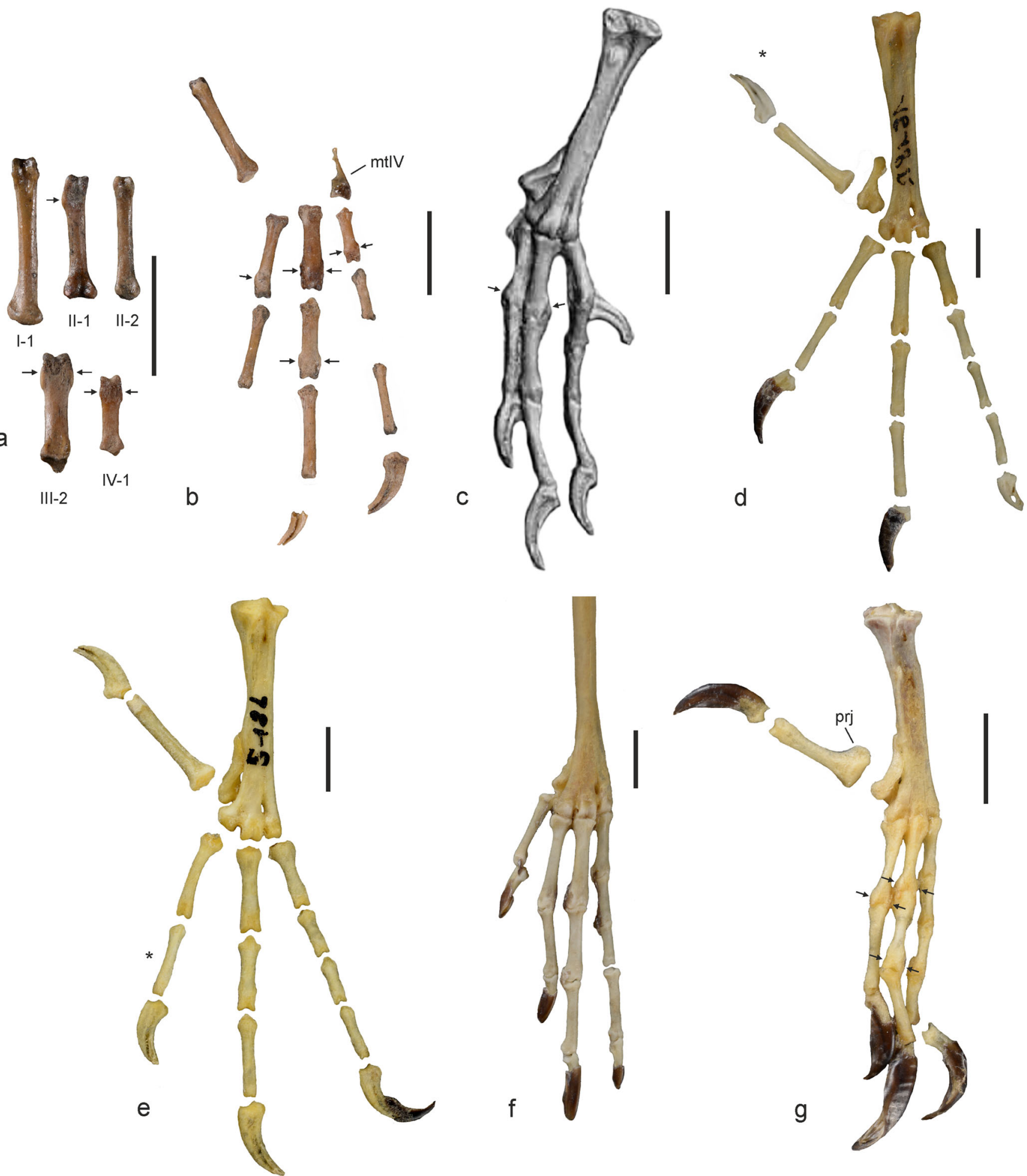

Fig. 5 Septencoracias cf. morsensis from the early Eocene London Clay of Walton-on-the-Naze (SMF Av 655), pedal phalanges in comparison to extant Coraciidae, Brachypteraciidae, and Meropidae. a $S$. cf. morsensis, selected pedal phalanges (numbered) in plantar view. b Left foot of $S$. cf. morsensis. c Left foot of the holotype of Septencoracias morsensis (surface scan, from Bourdon et al. 2016; published under a Creative Commons Attribution 4.0 International License) with surrounding matrix digitally removed (see Fig. $7 \mathrm{~b}$ for the unaltered image). d Right foot

(mirrored) of Coracias garrulus (Coraciidae); the asterisk indicates a phalanx from the contralateral foot. e Left foot of Eurystomus glaucurus (Coraciidae); the asterisk indicates a mirrored phalanx from the contralateral foot. f Left foot of Uratelornis chimaera (Brachypteraciidae); the proximal portion of the long tarsometatarsus is not shown. $\mathbf{g}$ Left foot of $M$. apiaster (Meropidae). The arrows indicate the widening of the distal sections of the phalanges. $m t I V$ trochlea metatarsi IV, prj projection formed by proximal end of first phalanx of hallux. Scale bars equal $5 \mathrm{~mm}$ 


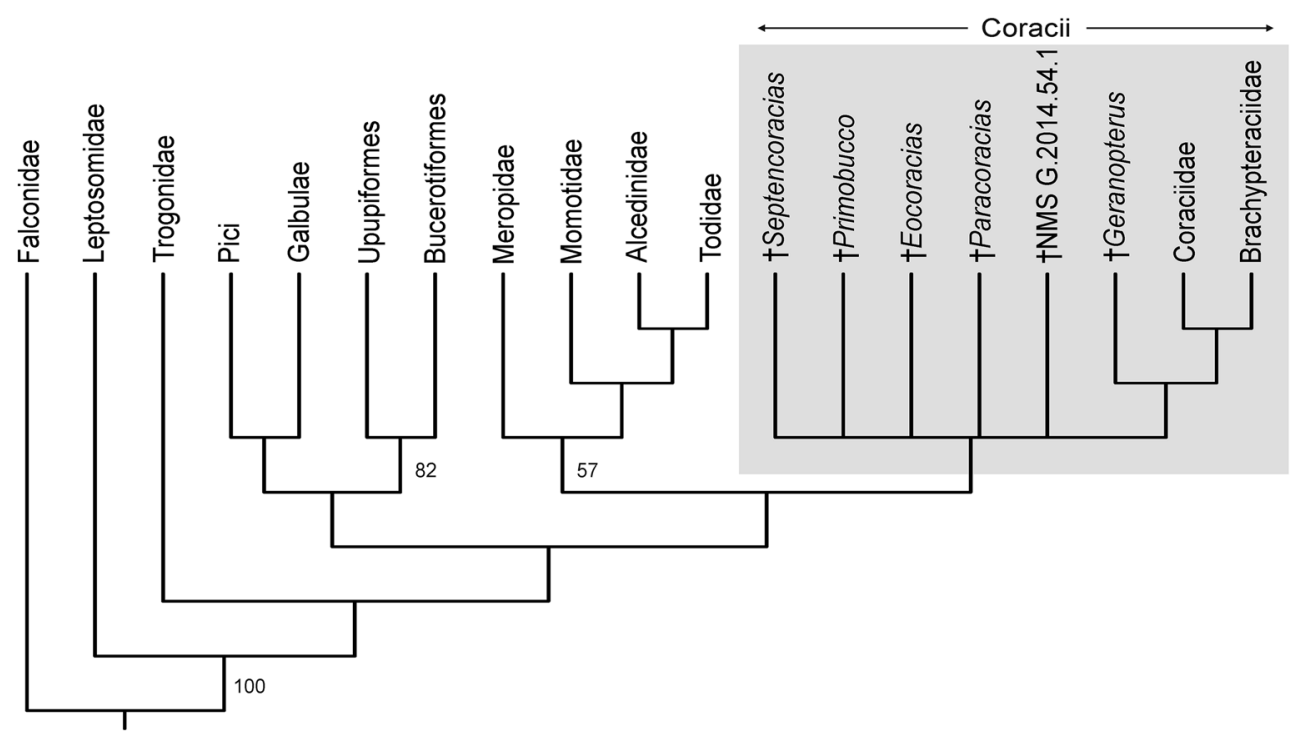

Fig. 6 Strict consensus tree of five most parsimonious trees ( $L=119$; CI $=0.52 ; \mathrm{RI}=0.62$ ) resulting from the analysis of the primary data set; bootstrap support values $>50 \%$ are shown next to the nodes. Extinct taxa

vasculare distale very large (ch. 47); and tarsometatarsus, canalis interosseus distalis plantarly open (ch. 48).

The primary analysis supported a clade including the Meropidae, Alcedinidae, Momotidae, and Todidae, which was also obtained in other analyses of morphological data (e.g. Clarke et al. 2009: fig. 9; Bourdon et al. 2016). Based on the results of current molecular analyses, a second analysis was therefore performed that was constrained to a sister group relationship between the Meropidae and the Coracii. This analysis likewise supported a placement of Septencoracias in the Coracii (not shown).

\section{Discussion}

An assignment of the fossil from Walton-on-the-Naze to the Coraciiformes (the clade including the Meropidae, Alcedinides, and Coracii) is supported by a ventrally prominent condylus medialis of the quadrate, a ventrally directed projection on the proximal portion of the os metacarpale minus, and a tibiotarsus with a lateral tuberositas retinaculi extensori that forms a prominent, edge-like projection just proximal of the condylus lateralis. The combination of these features is only found in rollers and ground rollers (Coracii).

The new London Clay specimen has the size of an average bee-eater and is smaller than the partial roller skeleton from the Isle of Sheppey, which was reported by Mayr and Walsh (2018). In size and morphology, the fossil closely corresponds to Septencoracias morsensis, which stems from the coeval and geographically proximate Fur Formation. In particular, an assignment to Septencoracias is supported by the unusual widening of the distal ends of the proximal pedal phalanges of are indicated with a dagger; specimen NMS G.2014.54.1 is the unnamed stem group roller from the Isle of Sheppey described by Mayr and Walsh (2018)

the three anterior toes, which does not occur in the Primobucconidae, Eocoracias, Paracoracias, and crown group Coracii. However, the new fossil shows some minor differences in the proportions of the pedal phalanges, which is why a species-level referral to $S$. morsensis is only tentative (the ratio of carpometacarpus length to the length of the first phalanx of the hallux, for example, is 2.59 in SMF Av 655 but $2.07 / 2.17$ in the $S$. morsensis holotype).

The present analyses support an assignment of Septencoracias to the Coracii, but the character evidence for this placement is only moderate. Of the six characters that were optimised as apomorphies of stem and crown group rollers, two are unknown for Septencoracias (ch. 3: processus postorbitales strongly elongated; ch. 6: large foramen for the ramus occipitalis of arteria ophthalmica externa). A third character represents a reversal into the plesiomorphic state (ch. 36: os metacarpale minus not exceeding os metacarpale majus). The remaining three characters, which were optimised as synapomorphies of Septencoracias, are a prominent, edge-like lateral tuberositas retinaculi extensori (ch. 42), a large foramen vasculare distale (ch. 47), and a plantarly open canalis interosseus distalis (ch. 48). The latter feature is visible on a tarsometatarsus from the early Eocene of Egem in Belgium, which was tentatively assigned to Septencoracias by Mayr and Smith (2019). Concerning the taxa included in the present analysis, a plantarly open canalis interosseus distalis is only found in the Coracii. However, the presence of a canalis interosseus distalis is plesiomorphic for neornithine birds, and this canal is completely reduced in the Meropidae and Alcedinides so that it actually cannot be determined whether the stem species of these taxa had a plantarly open canal. 
Bourdon et al. (2016) noted that "[p]lacement of Septencoracias within the rollers (Coracii) is strongly supported. Septencoracias unambiguously shares with extant and extinct rollers the derived presence of a small depression on the cranial face of humeral head (...); a narrow and elongate brachial fossa of the humerus; a ventrally protruding projection on the ventral side of the proximal end of minor metacarpal (...); a deep dorsal infracotylar fossa on the tarsometatarsus (...); a sharp distal part of medial margin of tarsometatarsal shaft (...); a greatly enlarged distal vascular foramen of tarsometatarsus prolonged by a marked groove" (Bourdon et al. 2016: 6). However, I am unable to comprehend the first of these characters ("small depression on cranial face of humeral head"), and a ventral projection on the minor metacarpal and a sharp distal part of the medial margin of the tarsometatarsal shaft are also present in the Meropidae. The narrow and elongate fossa musculi brachialis is an apomorphy of the Coraciidae and is absent in the Brachypteraciidae and Geranopteridae. The deep infracotylar fossa is a plesiomorphic trait, which is present in the Leptosomidae and Falconidae (as well as numerous other neornithine taxa).

In light of current molecular phylogenies, which support a sister group relationship between the Coracii and the Meropidae (see introduction), it is notable that the new fossil reveals previously unrecognised derived features that are shared with the Meropidae but absent in the Coracii. One of these is a widening of the distal section of the proximal phalanges of the three anterior toes, which to the best of my knowledge is unknown from any avian taxon other than Septencoracias and the Meropidae. As shown by the new fossil, the cotyla quadratojugalis of the quadrate bone of Septencoracias is furthermore shallow, whereas it is cup-like in the Coracii and in the Alcedinides. Also unlike in the Coracii, but as in the Meropidae, the long mandible of Septencoracias is mediolaterally narrow.

Overall, Septencoracias is certainly more similar to rollers than to crown group Meropidae, which are highly specialised birds that predominantly forage on flying hymenopterans. Adaptations to this feeding strategy include a greatly elongated and very narrow beak as well as long distal wing elements that enable a fast flight. However, a roller-like skeletal morphology is likely to be plesiomorphic for the Coraciiformes, because it also occurs in close relatives of coraciiform birds, such as the Leptosomiformes and the piciform Galbulae, as well as in the coraciiform Momotidae (Alcedinides). If the Meropidae are the sister taxon of the Coracii, their stem species therefore probably had a more roller-like body plan.

The Meropidae have no Palaeogene fossil record. Based on calibrated molecular data, the divergence between the Coracii and Meropidae was estimated at 55.6 Ma (52.7$57.4 \mathrm{Ma}$ ) by McCullough et al. (2019). With 54.6-55 million years, the age of the new fossil is only slightly younger than the above mean divergence date and is within the confidence interval of this date. Even though the hypothesis that Septencoracias represents an early stem group representative of the Meropidae that retained plesiomorphic Coracii-like traits is obvious, it gains no support in current parsimony-based analyses. The derived features shared by Septencoracias and the Meropidae are therefore most likely either plesiomorphic and were lost in the Coracii or they represent parallelisms that evolved convergently in Septencoracias and the Meropidae.

The functional significance of the widening of the pedal phalanges in the Meropidae is unknown. Most likely, this unusual feature is related to the syndactyl feet and breeding habits of these birds, in which the proximal phalanges of the toes are firmly linked by connective tissue and the clutches are deposited in self-excavated earth tunnels. However, the pedal phalanges are not widened in other syndactyl birds with similar nesting habits (Alcedinidae, Momotidae, and Todidae), and the adaptive advantage of the widened pedal phalanges of the Meropidae still has to be identified.

In any case, Septencoracias appears to have differed from extant rollers in its ecological preferences and foraging mode. The narrower mandible may indicate a predominantly insectivorous diet, whereas the more broad-billed rollers also take smaller invertebrates. If the widening of the pedal phalanges indicates that Septencoracias was digging burrows for its clutches, it would also have differed in its nesting habits from the species of the Coraciidae, which nest in tree cavities. The breeding biology of the Brachypteraciidae is more varied, and whereas the short-legged ground roller (Brachypteracias leptosomus), which is the sister taxon of other species of the Brachypteraciidae (Mayr and Mourer-Chauviré 2000; Kirchman et al. 2001), likewise nests in tree cavities, other species of the Brachypteraciidae excavate burrows in the ground (Langrand 2001).

It is finally noted that the leg bones of Septencoracias and other stem group Coracii differ markedly from those of the recently described putative stem group roller Ueekenkcoracias tambussiae from the early Eocene of the Argentinean part go Patagonia (Degrange et al. 2021). This species is only known from a rather poorly preserved leg (Fig. 7a), the bones of which are quite different from the corresponding elements of the Coracii, with the tarsometatarsus being notably stouter, the pedal phalanges more robust, and the ungual phalanx of the second toe much larger (the unusually large claw is actually a highly distinctive feature of the species that was not mentioned in its description). With regard to these traits and apart from a proportionally somewhat longer tibiotarsus, Ueekenkcoracias more closely resembles Palaeopsittacus from the early Eocene of Europe (Fig. 7c; Mayr 2003). The affinities of this latter taxon are not well-constrained, but it is certainly not a representative of the Coraciiformes and likely to be more closely related to taxa of the Strisores, such as the Steatornithidae or Podargidae. 


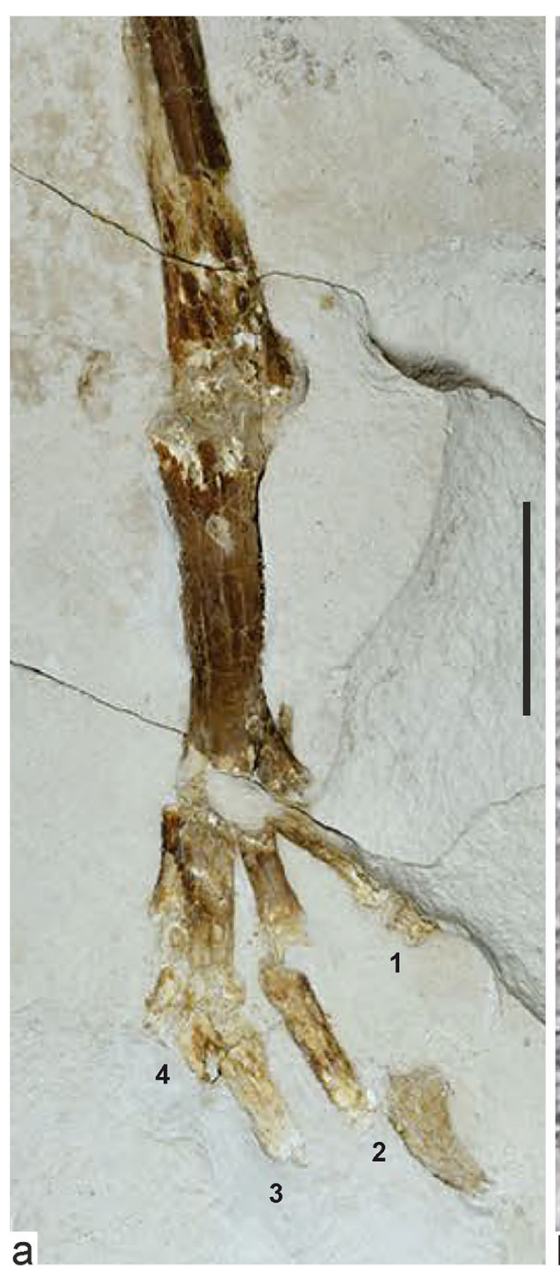

Fig. 7 Left foot of (a) the right foot of the holotype of Ueekenkcoracias tambussiae from the early Eocene of Argentina (holotype, from Degrange et al. 2021; published under a Creative Commons Attribution 4.0 International License) in comparison to (b) the left foot of the holotype of Septencoracias morsensis (surface scan, from Bourdon et al. 2016;

\section{Appendix 1. Character descriptions}

1. Skull, largely or completely ossified septum nasale: absent (0), present (1).

2. Skull, descending process of os lacrimale medially expanded: no (0), yes (1).

3. Skull, processus postorbitalis, greatly elongated, touching (or nearly touching) the jugal bar: no (0), yes (1).

4. Skull, processus postorbitalis, with cranial projection (Mayr and Mourer-Chauviré 2000: fig. 4A): no (0), yes (1).

5. Skull, temporal fossae deep and nearly reaching midline of skull: no (0), yes (1).

6. Skull, very large foramen for the ramus occipitalis of the arteria ophthalmica externa (Mayr and Walsh 2018): absent (0), present (1).

7. Skull, columella with large, hollow, bulbous basal and footplate area that exhibits a large fenestra on one side (Feduccia 1977): no (0), yes (1).

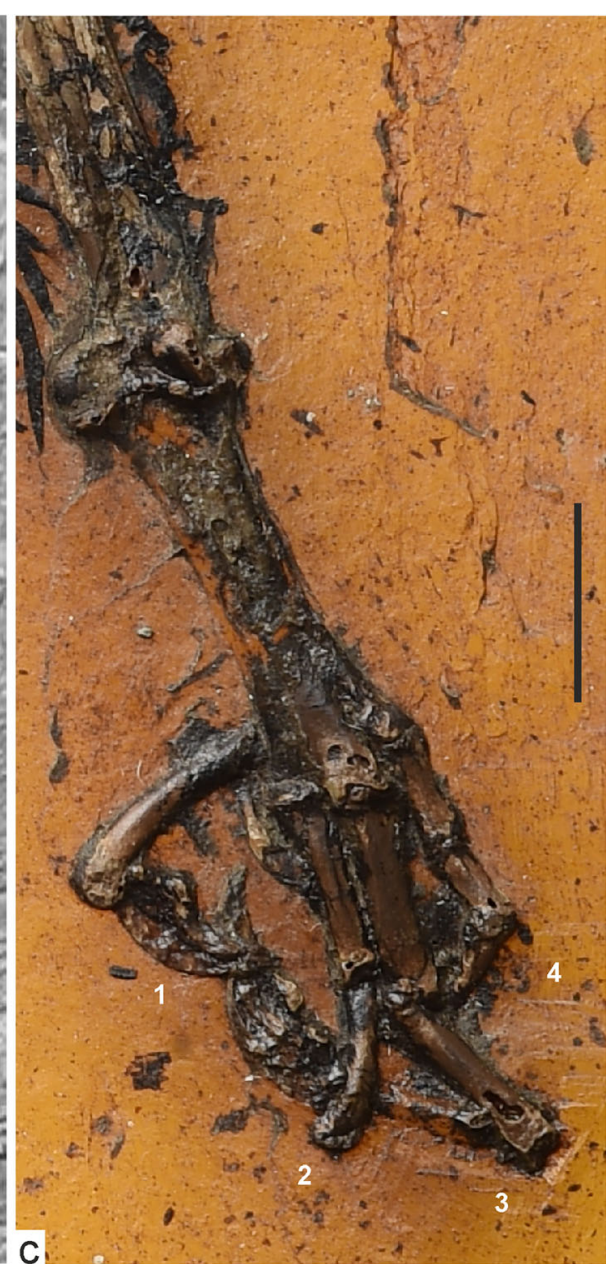

published under a Creative Commons Attribution 4.0 International License) and (c) the left foot of Palaeopsittacus cf. georgei from the latest early or earliest middle Eocene of Messel (SMNK.PAL.3834a). The toes are numbered. Scale bars equal $10 \mathrm{~mm}$

8. Skull, number of scleral ossicles: 14 or 15 (0), 13 (1).

9. Quadrate, cotyla quadratojugalis: deeply concave $(0)$, shallow (1).

10. Quadrate, condylus medialis rostrocaudally short and ventrally prominent: no (0), yes (1).

11. Quadrate, foramen pneumaticum mediale: present (0), absent (1).

12. Quadrate, caudal surface of tip of processus oticus with pneumatic foramina: no (0) yes (1).

13. Mandible, area of pars symphysialis with subrectangular cross section: absent (0), present (1).

14. Number of praesacral vertebrae: 20 or more (0), 18 or 19 (1).

15. Fourth cervical vertebra, osseous bridge connecting the processus transversus with the processus articularis caudalis: absent (0), present (1).

16. Fourth cervical vertebra, processus spinosus long and well-defined: no (0), yes (1). 
17. Corpus of thoracic vertebrae with distinct ovate fossae on lateral surfaces: no (0), yes (1).

18. Pygostyle with large, shield-like discus pygostyli with sharply defined, ridge-like lateral margins: no (0), yes (1).

19. Furcula with processus acrocoracoideus and processus acromialis well-developed, forming a plate-like extremitas omalis of subtriangular shape: no (0), yes (1).

20. Furcula, extremitas omalis with distinct, laterally protruding facies articularis acrocoracoidea: no (0), yes (1).

21. Furcula, scapi clavicularum very narrow at extremitas sternalis (Mayr 1998: fig. 16): no (0), yes (1).

22. Furcula with well-developed apophysis furculae: no (0), yes (1). In the Coraciidae, an apophysis furculae is absent in Eurystomus but present in Coracias; in the Galbulae it is absent in Galbulidae but present in Bucconidae.

23. Scapula, acromion distinctly bifurcate, with additional medial process: no (0), yes (1).

24. Coracoid, processus procoracoideus greatly reduced: no (0), yes (1).

25. Coracoid, foramen nervi supracoracoidei: present (0), absent (1).

26. Coracoid, extremitas sternalis with notch in margo medialis: no (0), yes (1).

27. Scapula, acromion distinctly bifurcate, i.e. with an additional dorsal process: no (0), yes (1).

28. Sternum, well-developed spina externa rostri: absent (0), present (1).

29. Caudal margin of sternum: with four notches/fenestrae (0), with two notches/fenestrae (1).

30. Humerus, processus flexorius prominent and reaching distally well beyond distal margin of condylus ventralis: no (0), yes (1).

31. Ulna, olecranon very long, narrow, and pointed; tuberculum ligamenti collateralis ventralis strongly protruding: no (0), yes (1).

32. Carpometacarpus, distinctly exceeding coracoid in length: no (0), yes (1).

33. Carpometacarpus, proximal end of metacarpale minus forming a ventral projection: no (0), yes (1).

34. Carpometacarpus, processus intermetacarpalis: absent or small (0), well-developed, reaching the os metacarpale minus (1), absent but tendon of musculus extensor carpi ulnaris inserts on the os metacarpale minus as it does in taxa with a processus intermetacarpalis (2).

35. Carpometacarpus, ventral part of trochlea carpalis cranio-caudally narrow and proximodistally elongate, slanting caudally towards the midline of the caudal side, fovea carpalis caudalis marked: no (0), yes (1).

36. Carpometacarpus, os metacarpale minus protruding much farther distally than os metacarpale majus: no (0), yes (1).

37. Os carpi radiale, proximodistally wide, with well-defined, narrow sulcus for the tendon of musculus extensor longus alulae (see Mayr 2014): no (0), yes (1).
38. Phalanx proximalis digiti majoris, proximal end with large, proximally directing process: no (0), yes (1).

39. Pelvis, processus terminalis ischii very narrow and slender, touching pubis at an angle of $45^{\circ}-90^{\circ}$, fenestra ischiopubica very wide: no (0), yes (1).

40. Femur, pneumatic foramen on cranio-lateral side of proximal end: absent (0), present (1).

41. Tibiotarsus, distal end mediolaterally narrow, with proximodistally long condyles: no (0), yes (1).

42. Tibiotarsus, distal end, lateral tuberositas retinaculi extensori forming a prominent, edge-like projection immediately proximal of the condylus lateralis: no (0), yes (1).

43. Tarsometatarsus, hypotarsus passing into a welldeveloped crista medianoplantaris: no (0), yes (1).

44. Tarsometatarsus, fossa parahypotarsalis medialis marked and proximal part of margo medialis forming a sharp ridge: no (0), yes (1).

45. Tarsometatarsus, hypotarsus with closed, or nearly closed, canal for tendon of musculus flexor digitorum longus: no (0), yes (1), condition in Trogonidae, with common canal for tendons of musculus flexor digitorum longus, $m$. flexor perforatus digiti 2 , and $\mathrm{m}$. flexor perforans et perforatus digiti 2 (2). For Septencoracias, this character was scored after a specimen described by Mayr and Smith (2019).

46. Tarsometatarsus, hypotarsus with closed canal for tendon of musculus flexor hallucis longus: no (0), yes (1). For Septencoracias, this character was scored after a specimen described by Mayr and Smith (2019).

47. Tarsometatarsus, foramen vasculare distale very large: no (0), yes).

48. Tarsometatarsus, canalis interosseus distalis: present, closed (0), present, plantarly open (1), absent (2).

Tarsometatarsus, incisurae intertrochleares very short: no (0), yes (1). For Septencoracias, this character was scored after a specimen described by Mayr and Smith (2019).

50. Tarsometatarsus, trochlea metatarsi IV: not as follows (0), with plantarly directed, wing-like flange (1), with large trochlea accessoria that is separated by a furrow from the main trochlea (2).

51. Hallux, proximal end of first phalanx greatly widened: no (0), yes (1).

52. Pedal phalanges, distal end of first phalanges of three anterior toes mediolaterally widened: no (0), yes (1).

53. Feet extensively syndactyl, i.e. third and fourth toe coalescent at least over length of proximal phalanx of third toe: no (0), yes (1).

54. Musculus ambiens: present (0), absent (1).

55. Musculus flexor hallucis longus, origin with three heads, iliofibularis tendon passes lateral to lateral head: no (0), yes (1).

56. Musculus flexor hallucis longus, tendon supplying hallux: yes (0), no (1). 
57. Hatchlings, mandible distinctly exceeding upper beak in length: no (0), yes (1); after Manegold (2005).

58. Hatchlings, terminal end of upper beak forming distinct hook: no (0), yes (1); after Manegold (2005).

\section{Appendix 2. Character matrix used in the phylogenetic analysis. The Falconidae were specified as outgroup taxon. Specimen NMS G.2014.54.1 is the unnamed stem group roller from the Isle of Sheppey described by Mayr and Walsh (2018).}

Characters and character states

Taxa $\begin{array}{lllllllllllllllllllllllllllll}1 & 2 & 3 & 4 & 5 & 6 & 7 & 8 & 9 & 10 & 11 & 12 & 13 & 14 & 15 & 16 & 17 & 18 & 19 & 20 & 21 & 22 & 23 & 24 & 25 & 26 & 27 & 28 & 29\end{array}$

Falconidae

Leptosomidae

$\begin{array}{llllllllllllllllllllllllllllll}1 & 0 & 0 & 0 & 0 & 0 & 0 & 0 & 0 & 0 & 0 & 0 & 01 & 0 & 0 & 0 & 0 & 0 & 0 & 1 & 0 & 0 & 0 & 0 & 0 & 0 & 0 & 1 & 1\end{array}$
$\begin{array}{lllllllllllllllllllllllllllll}1 & 0 & 1 & 0 & 0 & 0 & 0 & 1 & 0 & 0 & 0 & 0 & 0 & 1 & 0 & 0 & 0 & 0 & 0 & 1 & 0 & 0 & 0 & 0 & 0 & 0 & 0 & 0 & 0\end{array}$

Alcedinidae

Meropidae

Momotidae

Todidae

Coraciidae

Brachypteraciidae

Upupiformes

Bucerotiformes

Pici

Galbulae

Trogonidae

Septencoracias

$\begin{array}{lllllllllllllllllllllllllllllll}1 & 1 & 0 & 0 & 1 & 0 & 1 & 1 & 0 & 0 & 1 & 1 & 0 & 1 & 1 & 1 & 0 & 0 & 1 & 0 & 1 & 0 & 1 & 0 & 1 & 1 & 1 & 1 & 0\end{array}$

Primobucco

Eocoracias

Paracoracias

Geranopterus

$\begin{array}{llllllllllllllllllllllllllllllllll}\text { NMS G.2014.54.1 } & ? & ? & 1 & 0 & 0 & 1 & ? & ? & ? & ? & ? & 0 & ? & ? & ? & ? & ? & ? & ? & ? & ? & ? & ? & ? & ? & ? & ? & ? & ?\end{array}$

Characters and character states

\begin{tabular}{lllllllllllllllllllllllllllllllllllll}
\hline Taxa & 30 & 31 & 32 & 33 & 34 & 35 & 36 & 37 & 38 & 39 & 40 & 41 & 42 & 43 & 44 & 45 & 46 & 47 & 48 & 49 & 50 & 51 & 52 & 53 & 54 & 55 & 56 & 57 & 58 \\
\hline Falconidae & 0 & 0 & 01 & 1 & 0 & 0 & 0 & 0 & 0 & 0 & 1 & 0 & 0 & 1 & 0 & 0 & 0 & 0 & 0 & 0 & 0 & 0 & 0 & 0 & 0 & 0 & 0 & 0 & 0 \\
Leptosomidae & 0 & 0 & 1 & 1 & 0 & 0 & 1 & 0 & 0 & 0 & 0 & 0 & 0 & 0 & 0 & 1 & 1 & 0 & 0 & 0 & 1 & 0 & 0 & 0 & 1 & 0 & 0 & $?$ & $?$ \\
Alcedinidae & 0 & 0 & 0 & 0 & 1 & 0 & 1 & 1 & 0 & 0 & 0 & 0 & 1 & 1 & 1 & 1 & 0 & 1 & 2 & 0 & 0 & 1 & 0 & 1 & 1 & 0 & 1 & 1 & 1 \\
Meropidae & 0 & 0 & 0 & 1 & 0 & 0 & 1 & 1 & 0 & 0 & 0 & 0 & 0 & 1 & 1 & 1 & 0 & 0 & 2 & 0 & 0 & 1 & 1 & 1 & 1 & 0 & 1 & 1 & 1 \\
Momotidae & 0 & 0 & 0 & 0 & 0 & 1 & 1 & 1 & 0 & 0 & 0 & 0 & 0 & 1 & 1 & 1 & 0 & 0 & 2 & 0 & 0 & 1 & 0 & 1 & 1 & 0 & 1 & $?$ & 1 \\
Todidae & 0 & 0 & 0 & 0 & 1 & 0 & 1 & 1 & 0 & 0 & 0 & 0 & 0 & 1 & 1 & 1 & 0 & 0 & 2 & 0 & 0 & 1 & 0 & 1 & 1 & 0 & 1 & $?$ & 1 \\
Coraciidae & 0 & 0 & 0 & 1 & 1 & 0 & 0 & 1 & 0 & 0 & 0 & 1 & 1 & 1 & 1 & 1 & 0 & 1 & 1 & 0 & 0 & 0 & 0 & 0 & 1 & 0 & 0 & 1 & 1 \\
Brachypteraciidae & 0 & 0 & 0 & 1 & 1 & 1 & 1 & 1 & 0 & 0 & 0 & 1 & 1 & 1 & 1 & 1 & 0 & 1 & 1 & 0 & 0 & 0 & 0 & 0 & 1 & 0 & 0 & $?$ & $?$ \\
Upupiformes. & 1 & 1 & 0 & 0 & 2 & 1 & 1 & 1 & 0 & 1 & 1 & 0 & 1 & 1 & 1 & 1 & 1 & 0 & 2 & 1 & 0 & 01 & 0 & 1 & 1 & 0 & 0 & 1 & 0 \\
Bucerotidae & 1 & 0 & 0 & 0 & 2 & 0 & 1 & 1 & 0 & 1 & 1 & 0 & 0 & 1 & 1 & 1 & 1 & 0 & 2 & 1 & 0 & 0 & 0 & 1 & 1 & 0 & 0 & 1 & 0 \\
Pici & 1 & 1 & 0 & 0 & 1 & 1 & 1 & 1 & 1 & 1 & 0 & 0 & 0 & 0 & 01 & 1 & 0 & 0 & 2 & 0 & 2 & 0 & 0 & 0 & 1 & 1 & 0 & 1 & 0 \\
Galbulae & 0 & 0 & 0 & 0 & 1 & 1 & 1 & 1 & 1 & 0 & 0 & 0 & 0 & 1 & 1 & 1 & 0 & 1 & 2 & 0 & 2 & 0 & 0 & 0 & 1 & 1 & 0 & 1 & 0 \\
Trogonidae & 0 & 0 & 0 & 0 & 0 & 0 & 1 & 0 & 0 & 01 & 0 & 0 & 0 & 1 & 0 & 2 & 01 & 0 & 2 & 0 & 0 & 0 & 0 & 1 & 1 & 0 & 0 & 0 & 0
\end{tabular}




\begin{tabular}{|c|c|c|c|c|c|c|c|c|c|c|c|c|c|c|c|c|c|c|c|c|c|c|c|c|c|c|c|c|}
\hline Septencoracias & 0 & 0 & $?$ & 1 & 0 & 0 & 0 & $?$ & 0 & 0 & $?$ & 0 & 1 & 1 & 1 & 1 & 0 & 1 & 1 & 0 & 0 & 0 & 1 & $?$ & $?$ & & & \\
\hline Primobucco & 0 & 0 & 0 & 1 & 0 & 0 & 0 & 1 & 0 & 0 & $?$ & $?$ & $?$ & 1 & 1 & $?$ & $?$ & 1 & $?$ & 0 & 0 & 0 & 0 & $?$ & $?$ & & & \\
\hline Eocoracias & 0 & 0 & 0 & 1 & 0 & 0 & 0 & $?$ & 0 & $?$ & $?$ & $?$ & $?$ & 1 & 1 & $?$ & $?$ & $?$ & $?$ & 0 & 0 & 0 & 0 & $?$ & $?$ & & & \\
\hline Paracoracias & 0 & 0 & 0 & $?$ & 0 & 0 & 0 & $?$ & 0 & $?$ & $?$ & 0 & $?$ & 1 & 1 & $?$ & $?$ & $?$ & $?$ & 0 & 0 & 0 & & $?$ & $?$ & & & \\
\hline Geranopterus & 0 & $?$ & 0 & 1 & 1 & 0 & 0 & $?$ & 0 & $?$ & $?$ & 1 & $?$ & $?$ & $?$ & $?$ & $?$ & 1 & 1 & 0 & 0 & 0 & & $?$ & $?$ & & & \\
\hline NMS G.2014.54.1 & $?$ & $?$ & $?$ & $?$ & $?$ & $?$ & $?$ & $?$ & $?$ & $?$ & 0 & $?$ & $?$ & $?$ & $?$ & $?$ & $?$ & $?$ & 0 & $?$ & $?$ & $?$ & & $?$ & $?$ & & & \\
\hline
\end{tabular}

Acknowledgements I am indebted to Jason Bergdahl for facilitating the acquisition of the collection of his father, the late Paul Bergdahl. The photos were taken by Sven Tränkner (SMF). Comments from the reviewers, Marco Pavia and Antoine Louchart, improved the manuscript.

Funding Open Access funding enabled and organized by Projekt DEAL.

\section{Declarations}

Conflict of interest The author declares that he has no conflict of interest.

Open Access This article is licensed under a Creative Commons Attribution 4.0 International License, which permits use, sharing, adaptation, distribution and reproduction in any medium or format, as long as you give appropriate credit to the original author(s) and the source, provide a link to the Creative Commons licence, and indicate if changes were made. The images or other third party material in this article are included in the article's Creative Commons licence, unless indicated otherwise in a credit line to the material. If material is not included in the article's Creative Commons licence and your intended use is not permitted by statutory regulation or exceeds the permitted use, you will need to obtain permission directly from the copyright holder. To view a copy of this licence, visit http://creativecommons.org/licenses/by/4.0/.

\section{References}

Aldiss, D. T. (2012). The stratigraphical framework for the Palaeogene successions of the London Basin, UK. British Geological Survey Open Report, OR/12/004, 1-87.

Bourdon, E., Kristoffersen, A. V., \& Bonde, N. (2016). A roller-like bird (Coracii) from the Early Eocene of Denmark. Scientific Reports, 6, 34050 .

Clarke, J. A., Ksepka, D. T., Smith, N. A., \& Norell, M. A. (2009). Combined phylogenetic analysis of a new North American fossil species confirms widespread Eocene distribution for stem rollers (Aves, Coracii). Zoological Journal of the Linnean Society, 157, 586-611.

Collinson, M. E., Adams, N. F., Manchester, S. R., Stull, G. W., Herrera, F., Smith, S. Y., Andrew, M. J., Kenrick, P., \& Sykes, D. (2016). X-ray micro-computed tomography (micro-CT) of pyrite-permineralized fruits and seeds from the London Clay Formation (Ypresian) conserved in silicone oil: a critical evaluation. Botany, 94, 697-711.

Degrange, F. J., Pol, D., Puerta, P., \& Wilf, P. (2021). Unexpected larger distribution of paleogene stem-rollers (Aves, Coracii): New evidence from the Eocene of Patagonia, Argentina. Scientific Reports, 11, 1363.

Elzanowski, A., \& Boles, W. E. (2015). A coraciiform-like bird quadrate from the Early Eocene Tingamarra local fauna of Queensland, Australia. Emu, 115, 110-116.

Feduccia, A. (1977). A model for the evolution of perching birds. Systematic Biology, 26, 19-31.

Forbes, H. O. (1884). Forbes's final idea as to the classification of birds. The Ibis, fifth series, 2, 119-120.
Goloboff, P. A. (1993). NONA version 2.0. published by the author.

Grande, L. (2013). The lost world of fossil lake. Snapshots from deep time. University of Chicago Press.

Hackett, S. J., Kimball, R. T., Reddy, S., Bowie, R. C. K., Braun, E. L., Braun, M. J., Chojnowski, J. L., Cox, W. A., Han, K.-L., Harshman, J., Huddleston, C. J., Marks, B. D., Miglia, K. J., Moore, W. S., Sheldon, F. H., Steadman, D. W., Witt, C. C., \& Yuri, T. (2008). A phylogenomic study of birds reveals their evolutionary history. Science, 320, 1763-1767.

Jolley, D. W. (1996). The earliest Eocene sediments of eastern England: an ultra-high resolution palynological correlation. Geological Society, London, Special Publications, 101, 219-254.

Kirchman, J. J., Hackett, S. J., Goodman, S. M., Bates, J. M., \& Prum, R. (2001). Phylogeny and systematics of ground rollers (Brachypteraciidae) of Madagascar. The Auk, 118, 849-863.

Ksepka, D. T., \& Clarke, J. A. (2010). Primobucco mcgrewi (Aves: Coracii) from the Eocene Green River Formation: New anatomical data from the earliest constrained record of stem rollers. Journal of Vertebrate Paleontology, 30, 215-225.

Kuhl, H., Frankl-Vilches, C., Bakker, A., Mayr, G., Nikolaus, G., Boerno, S. T., Klages, S., Timmermann, B., \& Gahr, M. (2021). An unbiased molecular approach using 3'UTRs resolves the avian family-level tree of life. Molecular Biology and Evolution, 38, 108-127.

Langrand, O. (2001). Family Brachypteraciidae (Ground-rollers). In J. del Hoyo, A. Elliott, \& J. Sargatal (Eds.), Handbook of the birds of the world, Volume 6: Mousebirds to Hornbills (pp. 378-388). Lynx Edicions.

Linnaeus, C. (1758). Systema naturae per regna tria naturae (Vol. 2, 10th ed.). L. Salmii.

Manegold, A. (2005). Zur Phylogenie und Evolution der „,Racken”-, Specht- und Sperlingsvögel (,Coraciiformes”, Piciformes und Passeriformes: Aves). Dissertation.de.

Mayr, G. (1998). "Coraciiforme" und "piciforme" Kleinvögel aus dem Mittel-Eozän der Grube Messel (Hessen, Deutschland). Courier Forschungsinstitut Senckenberg, 205, 1-101.

Mayr, G. (2003). A postcranial skeleton of Palaeopsittacus Harrison, 1982 (Aves incertae sedis) from the Middle Eocene of Messel (Germany). Oryctos, 4, 75-82.

Mayr, G. (2009). Paleogene fossil birds. Springer.

Mayr, G. (2014). Comparative morphology of the radial carpal bone of birds and the phylogenetic significance of character variation. Zoomorphology, 133, 425-434.

Mayr, G., \& Mourer-Chauviré, C. (2000). Rollers (Aves: Coraciiformes s.s.) from the Middle Eocene of Messel (Germany) and the Upper Eocene of the Quercy (France). Journal of Vertebrate Paleontology, 20, 533-546.

Mayr, G., \& Smith, T. (2019). A diverse bird assemblage from the Ypresian of Belgium furthers knowledge of early Eocene avifaunas of the North Sea Basin. Neues Jahrbuch für Geologie und Paläontologie, Abhandlungen, 291, 253-281.

Mayr, G., \& Walsh, S. (2018). Exceptionally well-preserved early Eocene fossil reveals cranial and vertebral features of a stem group roller (Aves, Coraciiformes). Paläontologische Zeitschrift, 92, 715-726.

Mayr, G., Mourer-Chauviré, C., \& Weidig, I. (2004). Osteology and systematic position of the Eocene Primobucconidae (Aves, Coraciiformes sensu stricto), with first records from Europe. Journal of Systematic Palaeontology, 2, 1-12. 
McCullough, J. M., Moyle, R. G., Smith, B. T., \& Andersen, M. J. (2019). A Laurasian origin for a pantropical bird radiation is supported by genomic and fossil data (Aves: Coraciiformes). Proceedings of the Royal Society B, 286, 20190122.

Nixon, K. C. (2002). WinClada, version 1.00.08 [Computer software]. published by the author.

Prum, R. O., Berv, J. S., Dornburg, A., Field, D. J., Townsend, J. P., Lemmon, E. M., \& Lemmon, A. R. (2015). A comprehensive phylogeny of birds (Aves) using targeted next-generation DNA sequencing. Nature, 526, 569-573.

Wetmore, A., \& Miller, W. W. (1926). The revised classification for the fourth edition of the AOU Check-list. The Auk, 43, 337-346.

Publisher's note Springer Nature remains neutral with regard to jurisdictional claims in published maps and institutional affiliations. 